\title{
In-Situ Observation of Amorphous Oxide Deactivation Mechanism in Cu-Doped $\mathrm{CeO}_{2}$ Catalysis
}

J. Ciston, ${ }^{*}$ R. Si, ** J.A. Rodriguez, ${ }^{* *}$ J.C. Hanson, ${ }^{* *}$ and Y. Zhu***

* Center for Functional Nanomaterials, Brookhaven National Laboratory, Upton, NY 11973

** Department of Chemistry, Brookhaven National Laboratory, Upton, NY 11973

*** Department of Condensed Matter Physics and Materials Science, Brookhaven National Laboratory, Upton, NY 11973

The rarity of noble metal catalyst nanoparticles presents serious hurdles to the penetration of clean energy technologies on a global scale. However, catalytic materials based on the copper oxide framework are promising as more economical alternatives. The $\mathrm{Cu} / \mathrm{CeO}_{2}$ system is a very good catalyst for both the production of pure hydrogen via the water-gas shift reaction $\left(\mathrm{CO}+\mathrm{H}_{2} \mathrm{O} \rightarrow \mathrm{H}_{2}+\right.$ $\mathrm{CO}_{2}$ ), and $\mathrm{CO}$ oxidation [1]. In-situ reduction and oxidation of two different precursors of $\mathrm{Cu} / \mathrm{CeO} 2$ catalysts were studied by HREM imaging, electron diffraction, and EXAFS: $\mathrm{Ce}_{0.8} \mathrm{Cu}_{0.2} \mathrm{O}_{2}$ solid solutions and $\mathrm{CuO} / \mathrm{CeO}_{2}$ blends, both with particle sizes of 4-6 nm. These are some of the first results obtained from the FEI Titan Environmental TEM with post-objective $3^{\text {rd }}$ order aberration corrector at the Center for Functional Nanomaterials at Brookhaven National Laboratory, which is capable of atomic resolution at pressures up to 5 torr and temperatures of up to $800 \mathrm{C}$.

Metallic $\mathrm{Cu}$ precipitation was observed for both precursors upon annealing annealed at 350-400C in 1 torr of $\mathrm{H}_{2}$. However, the $\mathrm{Cu}$ precipitated from the solid solution precursor was more uniformly distributed. We have found the metallic precipitates to be $10-15 \mathrm{~nm}$ in size, which is 5 times larger than anticipated. During subsequent oxygen annealing at 1 torr and $400 \mathrm{C}, \mathrm{Cu}$ precipitated from the $\mathrm{CuO} / \mathrm{CeO} 2$ blend re-oxidized to form $\mathrm{CuO}$ as expected. However, the $\mathrm{Cu}$ precipitated from $\mathrm{Ce}_{0.8} \mathrm{Cu}_{0.2} \mathrm{O}_{2}$ solid solution behaved rather differently under oxidizing conditions, and neither oxidized to form $\mathrm{CuO}$, nor fully returned to the bulk $\mathrm{Ce}_{0.8} \mathrm{Cu}_{0.2} \mathrm{O}_{2}$ phase in solid solution as suggested by prior synchrotron diffraction and EXAFS results [2]. In this present analysis, Rietveld refinement of powder diffraction has shown that $60 \%$ of the $\mathrm{Cu}$ returns to a $\mathrm{Ce}_{1-\mathrm{x}} \mathrm{Cu}_{\mathrm{x}} \mathrm{O}_{2}$ solid solution, while the remainder was observed by in-situ TEM to form an amorphous copper oxide phase at the surface of $\mathrm{CeO}_{2}$ particles with copper in a +2 oxidation state indicated by EXAFS. [3]

References

[1] Q. Fu, et al., Science, 301 (2003) 935

[2] X.Q. Wang, et al., J Phys Chem B, 109 (2005) 19595.

[3] Research carried out in part at the Center for Functional Nanomaterials, Brookhaven National Laboratory, which is supported by the U.S. Department of Energy, Office of Basic Energy Sciences, under Contract No. DE-AC02-98CH10886. 

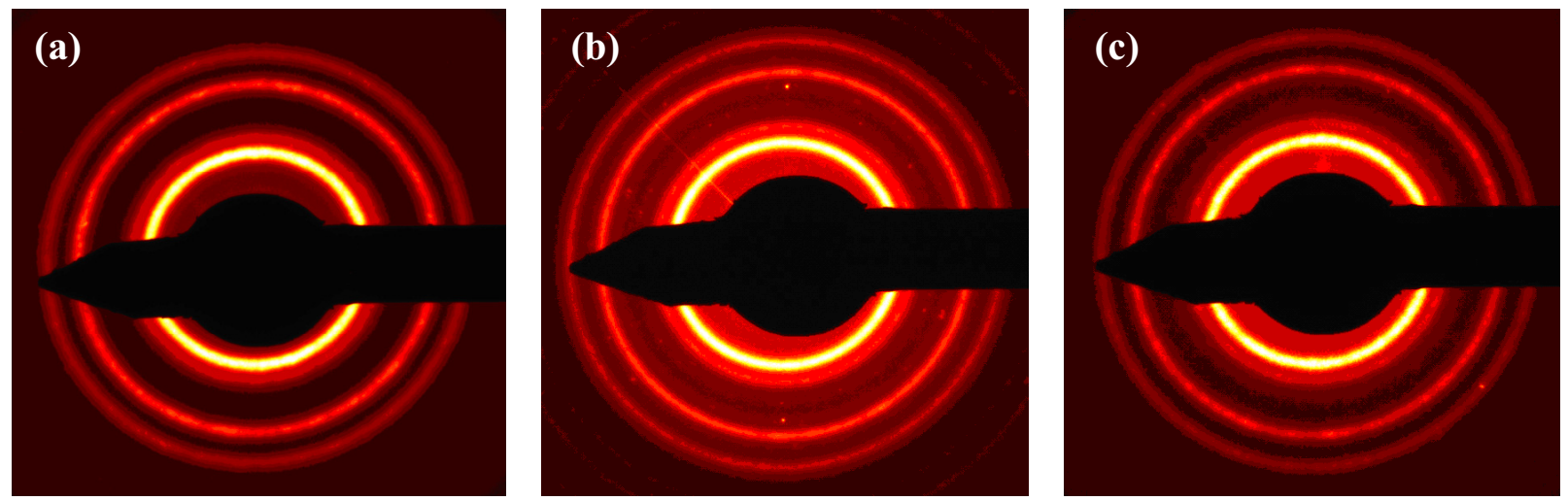

FIG 1: Electron diffraction patterns of $\mathrm{Ce}_{0.8} \mathrm{Cu}_{0.2} \mathrm{O}_{2}$ in a) initial state showing only $\mathrm{CeO}_{2}$-type rings, b) during $\mathrm{H}_{2}$ anneal (400 C, 1.5 torr) where additional $\mathrm{Cu}$ precipitate reflections have appeared, and c) during $\mathrm{O}_{2}$ anneal $\left(400 \mathrm{C}, 1.5\right.$ torr) where $\mathrm{Cu}$ reflections have vanished leaving only $\mathrm{CeO}_{2}$-type rings.
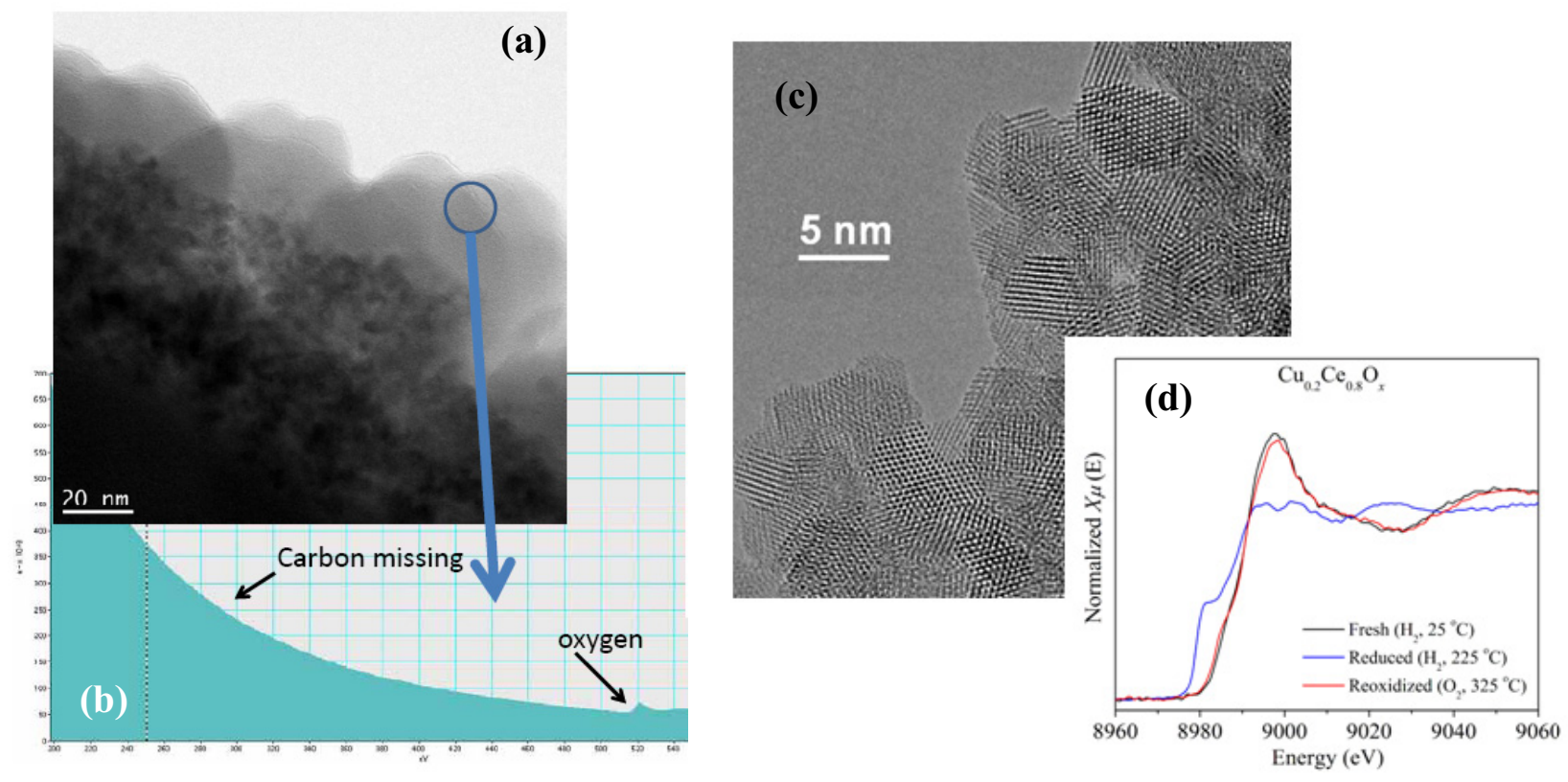

FIG 2: a) Bright field image of after in-situ annealing at 350C in 1 torr $\mathrm{H}_{2}$ followed by 1 torr $\mathrm{O}_{2}$ b) EELS of amorphous area indicating an oxide phase with no carbon deposition c) $\mathrm{Ce}_{0.8} \mathrm{Cu}_{0.2} \mathrm{O}_{2}$ asreceived d) $\mathrm{Cu}$-EXAFS spectra of $\mathrm{Ce}_{0.8} \mathrm{Cu}_{0.2} \mathrm{O}_{2}$ annealed as indicated showing a final amorphous oxide valence state of $2^{+}$, which is identical to the initial state. 